\title{
Ciencias ambientales como requerimiento básico para el desarrollo
}

\section{Environmental sciences as basic requirement for the development}

\author{
De La Ossa V, Jaime ${ }^{1^{\star}}$ Ph.D, Montes Vergara, Donicer ${ }^{1}$ Ph.D, \\ Pérez-Cordero, Alexander ${ }^{1}$ Ph.D.
}

${ }^{1}$ Universidad de Sucre, Facultad de Ciencias Agropecuarias, Colombia. Correspondencia: jaimedelaossa@yahoo.com

\begin{abstract}
Es evidente que la realidad ambiental actual muestra una acelerada destrucción de las fuentes de recursos naturales, sin duda, ya son visibles sus efectos negativos sobre la producción, la salud y la biodiversidad. Más que nunca se necesita un modelo ambiental que esté direccionado hacia la racionalidad como objetivo inminente, que sea vinculante entre los procesos naturales y el desarrollo social, y que esté transversalmente unido a la interdisciplinariedad para alcanzar una nueva metodología de aprendizaje, más honesta menos nociva, más conservacionista menos dilapidadora.
\end{abstract}

Dada la complejidad que se aborda en las ciencias ambientales, como lo señalan PEÑA y ROLDÁN (2012) el estudio del medio ambiente no pertenece a ninguna ciencia o disciplina; inicialmente se conceptuaba que la ecología y la biología eran las ciencias más adecuadas para estudiar las interrelaciones de los seres vivos con su entorno natural; sin embargo, pronto se comprendió que la coevolución de las culturas y la naturaleza, así como los efectos antropogénicos sobre ésta, no podían ser explicados solo desde perspectivas biológicas o ecológicas. No significa que no sean necesarias o que su papel haya pasado a un segundo plano, implica que la comprensión de los procesos ambientales va más allá y requiere la interdisciplinariedad, sin que una u otra rama de la ciencia o de la tecnología sea más importante que otra, todas son valiosas y de igual importancia, y deben tener una aplicación sinérgica.

Es claro que los cuestionamientos éticos y filosóficos, así como la impactante realidad negativa que se vive, indican que las teorías reduccionistas individuales, la cuantificación de las reservas naturales, la valoración del potencial productivo de éstas o la interacción simple entre sociedad y naturaleza requieren de la incorporación conceptual de los valores existenciales de espacio y tiempo (PEÑA y ROLDÁN, 2012). La deuda que nos determina como sociedad es de gran talla, estamos convocando un legado negativo que hemos sustentado en el bienestar actual de tipo individual, que en vez de producir oportunidades de desarrollo futuro nos está negando, como especie, las posibilidades de subsistencia: tristemente por causa del deterioro se ha conocido la importancia de muchos recursos por no decir todos los disponibles y se ha llegado a establecer lo impactante de su ausencia.

En nuestro caso, hablando regionalmente, la escasez de productos alimenticios, el cambio de los ciclos meteorológicos, la deforestación, la pérdida de biodiversidad, la cacería y la pesca indiscriminada, la contaminación de las fuentes de agua, la pérdida de cobertura vegetal, la pobreza, la violencia, la desigualdad social y económica, entre muchos otros problemas, requieren la intervención del sistema desde una perspectiva colegiada y amplia, en la cual serían una óptima opción de apoyo las ciencias ambientales.

\section{Referencias}

PEÑAS E.J.; ROLDÁN, CH.J. 2012. Las ciencias ambientales: un área del conocimiento para el desarrollo de enfoques interdisciplinarios. Ambiente y Sostenibilidad (2):38-43 